\title{
Preference for an Opioid/Benzodiazepine Mixture over an Opioid Alone Using a Concurrent Choice Procedure in Rhesus Monkeys
}

\author{
Peter F. Weed, Charles P. France, and Lisa R. Gerak \\ Departments of Pharmacology (P.F.W., C.P.F., L.R.G.) and Psychiatry (C.P.F.), and the Addiction Research, Treatment \& Training \\ Center of Excellence (P.F.W., C.P.F, L.R.G.), University of Texas Health Science Center at San Antonio, San Antonio, Texas \\ Received January 11, 2017; accepted April 7, 2017
}

\begin{abstract}
Increased abuse of opioids is contributing to an escalation in overdose deaths. Benzodiazepines are frequently abused with opioids, possibly because they increase the potency and/or effectiveness of opioids to produce reinforcing effects. This study used a concurrent-choice procedure to determine whether monkeys would choose to self-administer a mixture of the opioid remifentanil and the benzodiazepine midazolam over remifentanil alone. Initially, three monkeys could respond on one lever for saline and on a second lever for either remifentanil alone or midazolam alone. Thereafter, monkeys chose between a dose of remifentanil $(0.32 \mu \mathrm{g} / \mathrm{kg} /$ infusion) that did not change and a dose of remifentanil that varied across sessions; for some sessions, midazolam was combined with varying doses of remifentanil. All monkeys received more infusions of remifentanil $(0.0032-0.32 \mu \mathrm{g} / \mathrm{kg} /$ infusion) than saline, whereas only two
\end{abstract}

monkeys responded more for midazolam than for saline. When $0.32 \mu \mathrm{g} / \mathrm{kg} /$ infusion remifentanil was available on one lever and a dose of remifentanil that varied across sessions $(0.1-1 \mu \mathrm{g} / \mathrm{kg} / \mathrm{infusion})$ was available on the other lever, monkeys chose the larger dose. Combining $3.2 \mu \mathrm{g} / \mathrm{kg} /$ infusion midazolam with $0.32 \mu \mathrm{g} / \mathrm{kg} /$ infusion remifentanil increased responding for the mixture over $0.32 \mu \mathrm{g} / \mathrm{kg} /$ infusion remifentanil alone, although monkeys chose remifentanil alone over mixtures containing smaller doses of remifentanil. When $10 \mu \mathrm{g} / \mathrm{kg} / \mathrm{infusion}$ midazolam was combined with $0.1 \mu \mathrm{g} / \mathrm{kg} /$ infusion remifentanil, monkeys chose the mixture over $0.32 \mu \mathrm{g} / \mathrm{kg} /$ infusion remifentanil alone. Thus, monkeys prefer some opioid/benzodiazepine mixtures to larger doses of the opioid alone, suggesting that opioid/ benzodiazepine coabuse might be due to increased potency (and possibly effectiveness) of opioids to produce reinforcing effects.

\section{Introduction}

Opioid abuse is considered an epidemic, with more than 10 million Americans reporting nonmedical use of prescription opioids; abuse of heroin is also increasing, presumably because it is less expensive or easier to obtain than other opioids (Compton et al., 2016; Skolnick and Volkow, 2016). The recent escalation in opioid abuse has contributed to a dramatic increase in overdose deaths, which have nearly tripled since 2000 (Rudd et al., 2016). One factor that might play a role in both the abuse and overdose epidemics is the concomitant use of benzodiazepines. Many opioid abusers, including those in treatment programs, also abuse benzodiazepines, and coabuse predicts continued drug use, poorer treatment outcomes, and increased likelihood of overdose (Woody et al., 1975; Stitzer et al., 1981; San et al., 1993; Bleich et al., 1999; Peles et al., 2006; Kerr et al., 2007; Ghitza et al., 2008; Lavie et al., 2009; Darke et al., 2010; Eiroa-Orosa et al., 2010). Despite the well-documented coabuse of opioids and benzodiazepines (Woody et al., 1975; Stitzer et al., 1981; San et al., 1993; Gelkopf et al.1999; Gossop et al., 1999; Lavie et al., 2009), it is unclear why these mixtures are preferred and

The authors declare no conflict of interest.

This study was supported by the National Institutes of Health National Institute on Drug Abuse [Grants R21 DA039394, T32 DA031115] and by the Welch Foundation [Grant AQ-0039]. The content is solely the responsibility of the authors and does not necessarily represent the official views of the National Institutes of Health or the National Institute on Drug Abuse.

https://doi.org/10.1124/jpet.117.240200. few laboratory studies have systematically investigated this phenomenon.

Abuse liability of drugs is often assessed in the preclinical laboratory using single-response, self-administration procedures, which determine if a drug serves as positive reinforcer and therefore can predict whether the drug is likely to be abused by humans. This approach has identified positive reinforcing effects of opioids alone and benzodiazepines alone in humans and nonhuman primates (e.g., Griffiths and Weerts 1997; Gerak et al., 2009; Haney 2009) and has been used to examine self-administration of mixtures of opioids and other abused drugs (e.g., cocaine; Woolverton et al., 2008). A few studies have compared self-administration of a benzodiazepine alone after noncontingent administration of an opioid or of an opioid alone after noncontingent administration of a benzodiazepine. For example, in baboons, responding for the benzodiazepine flunitrazepam increased during chronic treatment with methadone, compared with responding for flunitrazepam before treatment began; however, that effect did not change when methadone treatment was discontinued, suggesting that either the change was permanent or it was not related to methadone dependence (Ator et al., 2005). Another study in humans found that responding for methadone decreased after acute administration of the benzodiazepine diazepam (Spiga et al., 2001). Although those findings provide some insight into the combined effects of opioids and benzodiazepines, there is no information on self-administration of mixtures in laboratory studies. 
One possible reason for the absence of data on the reinforcing effects of mixtures of opioids and benzodiazepines is that the procedures that are most commonly used (i.e., single-response, self-administration procedures) are not sensitive to the reinforcing effects of these drug mixtures. A different procedure might be more useful for studying opioid/benzodiazepine mixtures. Therefore, in the current study, a two-response self-administration procedure (i.e., choice) was established to test preference of monkeys for an opioid/benzodiazepine mixture over the opioid alone. Choice procedures have several advantages over single-response, self-administration procedures. First, they can be more sensitive than traditional procedures to reinforcing effects of drug mixtures (Ward et al., 2005; Freeman and Woolverton, 2011). Second, because choice procedures use the proportion of responses on each response alternative or proportion of reinforcers delivered as a measure of reinforcement, reinforcing effects can be assessed relatively independently of response rate, which makes these procedures especially useful for examining reinforcing effects under conditions where response rates are reduced. For the current study, rhesus monkeys were trained to respond on levers to receive infusions; the solution available for self-administration could be the same or different across the two response alternatives. Once the choice procedure was established, the solutions available for self-administration were changed systematically to determine whether monkeys preferred a mixture of an opioid and a benzodiazepine to an opioid alone. The opioid remifentanil and the benzodiazepine midazolam are often used in self-administration studies due to their relatively fast onset of action and short duration of action (Ko et al., 2002; Broadbear et al., 2005).

\section{Methods}

Subjects. One adult female (JA) and two adult male (HU and KI) rhesus monkeys participated in this study. These monkeys had histories of responding under fixed-ratio schedules and had received a variety of drugs (e.g., Koek et al., 2015; Collins et al., 2016). Body weights $(6.5-10.7 \mathrm{~kg})$ were maintained by providing primate chow (High Protein Monkey Diet; Harlan Teklad, Madison, WI), fresh fruit, and peanuts daily. Monkeys were housed individually under a 14/10-hour light/dark cycle with fresh water continuously available in the home cage. Monkeys were maintained in accordance with the Institutional Animal Care and Use Committee, The University of Texas Health Science Center at San Antonio, and the 2011 Guide for the Care and Use of Laboratory Animals (Institute of Laboratory Animal Resources on Life Sciences, National Research Council, National Academy of Sciences).

Surgery. Indwelling venous catheters were surgically implanted according to methods described elsewhere (Gerak et al., 2016). Monkeys received $10 \mathrm{mg} / \mathrm{kg}$ ketamine (subcutaneous; Henry Schein Animal Health, Dublin, $\mathrm{OH}$ ) with anesthesia maintained by isoflurane (Butler Animal Health Supply, Grand Prairie, TX) and oxygen delivered at a rate of $2 \mathrm{l} / \mathrm{min}$. A silicone double-lumen catheter (model SIL-C50-HSC1; Instech Solomon, San Antonio, TX) was placed in a vein (e.g., femoral or jugular) and tunneled subcutaneously to the midscapular region where each lumen was connected to a subcutaneous access port (model MID-C50; Access Technologies, Skokie, IL).

Apparatus. Subjects were seated in commercially available chairs (model R001; Primate Products, Miami, FL) and placed in custommade operant conditioning chambers that were ventilated and sound attenuating. Each chamber contained a response panel with two response levers; stimulus lights located above each lever could be illuminated either green or red. Before sessions, each port was connected to a separate syringe using a 20-g Huber-point needle (Access Technologies) and a 183-cm mini-volume catheter extension set (model 2C5687; Baxter Healthcare, Deerfield, IL). The size of the syringe varied depending on the size of the monkey (JA and KI: $30 \mathrm{ml}$ syringe; HU: $60 \mathrm{ml}$ syringe). Each syringe was placed in a syringe driver (model PHM-100; Med Associates, Inc.) and completion of the response requirement on a lever resulted in the delivery of the appropriate solution. The infusion rate was $2.3 \mathrm{ml} / \mathrm{min}$ (for a $30 \mathrm{ml}$ syringe) or $3.4 \mathrm{ml} / \mathrm{min}$ (for a $60 \mathrm{ml}$ syringe). Experimental events were controlled, and data were recorded by a computer that was connected to an interface and operating MedPC IV software (Med Associates, Inc., St. Albans, VT). Extraneous noise was masked by white noise in each chamber.

Procedure. Monkeys responded under a fixed-ratio 30 schedule for intravenous infusions. Daily sessions began with two forced trials followed by up to 24 choice trials. The beginning of trials was signaled by illuminating the green stimulus light above one (forced trials) or both (choice trials) levers; 30 consecutive responses on a lever below an illuminated stimulus light extinguished green lights, illuminated the red light above the lever on which the response requirement was completed, and activated the infusion pump to deliver the solution that was associated with responding on that lever for the session. The red light remained illuminated for 5 seconds. The infusion duration varied depending on the weight of the monkey, ranging from 17 to 24 seconds, and the concentration of drug in the syringe changed to obtain different unit doses. During the intertrial interval, which began upon completion of the response requirement and lasted 180 seconds, responses were recorded but had no programmed consequence; once the red light was extinguished, the chamber was dark for the remaining 175 seconds of the intertrial interval. The first two trials of the session were forced trials with one stimulus light illuminated and responding on one lever resulting in the delivery of an infusion; the order in which the two forced trials were presented varied randomly across sessions. During choice trials, which began only after completion of both forced trials, both stimulus lights were illuminated green and the response requirement could be completed on either lever. Sessions continued until 24 choice trials were completed or 100 minutes elapsed, whichever occurred first.

Monkeys initially responded for $0.32 \mu \mathrm{g} / \mathrm{kg} /$ infusion remifentanil on one lever and saline on the other lever. This dose maintains reliable responding in single-response, self-administration procedures (e.g., Woolverton et al., 2008) and is the smallest dose of remifentanil that is preferred over a food pellet in a concurrent-choice procedure (Maguire et al., 2013). To distinguish between the lever associated with drug and the one associated with saline, one of the two stimulus lights blinked green while the other light was solid green. The blinking green light signaled availability of drug for monkeys JA and HU and availability of saline for monkey KI. Once subjects chose infusions of remifentanil over saline during at least $80 \%$ of choice trials for at least one day, the lever designations were switched such that the lever that was previously associated with delivery of remifentanil was associated with delivery of saline and vice versa. At least four lever switches occurred for each subject before generating the current data set.

With saline available on one lever, dose-effect curves for remifentanil alone were determined beginning with $0.32 \mu \mathrm{g} / \mathrm{kg} / \mathrm{infusion}$ remifentanil available for responding on the other lever. Each unit dose of remifentanil was available for a minimum of 3 sessions and decreased when one of the following criteria was satisfied: 1) the number of remifentanil infusions delivered during choice trials in each of three consecutive sessions did not differ by more than $20 \%$ from the mean of those sessions, and there was no upward or downward trend in the total number of infusions or response rates during choice trials across those three sessions; 2) fewer than five infusions of remifentanil were self-administered during each of three consecutive sessions; or 3) seven sessions were conducted under a particular condition. When one of these criteria was satisfied, the unit dose of remifentanil was decreased by $1 / 2$ log unit with saline 
still available on the other lever; this process of decreasing the unit dose and satisfying the criteria continued until no more than 6 infusions of remifentanil were delivered in any of the last 3 sessions or $0.0032 \mu \mathrm{g} / \mathrm{kg} / \mathrm{infusion}$, whichever occurred first. Thereafter, the dose of remifentanil was increased to $0.32 \mu \mathrm{g} / \mathrm{kg} /$ infusion, the lever designation was switched, the visual stimulus associated with drug remained the same, and the remifentanil dose-effect curve was redetermined. Midazolam then replaced remifentanil, with saline available for responding on the other lever, beginning with a dose of $32 \mu \mathrm{g} / \mathrm{kg} /$ infusion. The midazolam dose was decreased as described above to generate the midazolam dose-effect curve once.

Upon completion of the dose-effect curves for remifentanil and midazolam, the blinking green stimulus light was replaced with a solid green light, thereby removing the distinct visual stimuli associated with different solutions. In addition, saline was replaced with a drug solution. Initially, monkeys could respond 30 times on either lever to receive $0.32 \mu \mathrm{g} / \mathrm{kg} /$ infusion remifentanil, which was available on both levers until the percentage of infusions received on a lever in each of three consecutive sessions did not vary by more than $10 \%$ of the mean of those 3 sessions. Once this criterion was satisfied, demonstrating that responding was stable, a mixture of $0.32 \mu \mathrm{g} / \mathrm{kg} /$ infusion remifentanil and $10 \mu \mathrm{g} / \mathrm{kg} /$ infusion midazolam replaced remifentanil alone on one lever with $0.32 \mu \mathrm{g} / \mathrm{kg} / \mathrm{infusion}$ remifentanil still available for responding on the other lever; this dose of remifentanil alone remained fixed throughout the experiment. Monkeys responded for these solutions until the criterion for stable responding was satisfied or for seven sessions, whichever occurred first, after which the dose of remifentanil in the mixture with $10 \mu \mathrm{g} / \mathrm{kg} /$ infusion midazolam was decreased by $1 / 2 \log$ unit with $0.32 \mu \mathrm{g} / \mathrm{kg} /$ infusion remifentanil available for responding on the other lever. The variable dose of remifentanil in the mixture continued to decrease in $1 / 2 \log$ unit increments every three to seven sessions, depending on the number of sessions needed to satisfy the criterion for stable responding, until infusions of the mixture accounted for less than $20 \%$ of the total number of infusions received during a session. Once this remifentanil dose-effect curve was generated, lever designations were switched and the dose of remifentanil in the mixture returned to $0.32 \mu \mathrm{g} / \mathrm{kg} /$ infusion, such that the variable dose of remifentanil available in the mixture with $10 \mu \mathrm{g} / \mathrm{kg} / \mathrm{infusion}$ midazolam was the same as the fixed dose of remifentanil available alone. The dose-effect curve for remifentanil in the mixture was then redetermined.

Next, with the fixed dose of $0.32 \mu \mathrm{g} / \mathrm{kg} /$ infusion remifentanil still available on one lever, a dose-effect curve for remifentanil alone was determined on the other lever beginning with a dose of $1 \mu \mathrm{g} / \mathrm{kg} / \mathrm{infusion}$. Once the criterion for stable responding was satisfied, the variable dose of remifentanil was decreased from $1 \mu \mathrm{g} / \mathrm{kg} /$ infusion in $1 / 2$ log unit increments until monkeys responded for the fixed dose of $0.32 \mu \mathrm{g} / \mathrm{kg} / \mathrm{infusion}$ remifentanil over the variable dose, such that the number of infusions of the variable dose of remifentanil was less than $20 \%$ of the total number of infusions received. Thereafter, the lever designation was switched, and the dose-effect curve for remifentanil alone was redetermined. Different doses of midazolam (3.2 or $32 \mu \mathrm{g} / \mathrm{kg} /$ infusion) were then combined with the variable dose of remifentanil, with the fixed dose of $0.32 \mu \mathrm{g} / \mathrm{kg} /$ infusion remifentanil available on the other lever, using the procedure described above for $10 \mu \mathrm{g} / \mathrm{kg} / \mathrm{infusion}$, and dose-effect curves for the variable dose of remifentanil mixed with each dose of midazolam were determined twice.

Drugs. Remifentanil hydrochloride (Sigma-Aldrich, St. Louis, MO) was dissolved in sterile saline. Midazolam hydrochloride (Hospira, Inc., Austin, TX; West-Ward Pharmaceuticals Corp., Eaton, NJ) was purchased as a solution and diluted in sterile saline. All drugs and drug mixtures were filtered through a $0.2 \mu \mathrm{m}$ syringe filter before sessions. Catheter patency was maintained by flushing and locking each lumen with $2.5 \mathrm{ml}$ of saline containing heparin (100 U/ml; Hospira Inc., Lake Forest, IL) after sessions.

Data Analyses. When drug was available on one lever and saline was available on the other lever, the number of infusions of each solution received during choice trials, overall response rate during choice trials, and cumulative drug intake were plotted as a function of unit dose of remifentanil or midazolam. To calculate rate, the number of responses emitted while the green stimulus lights were illuminated were added across levers and across choice trials (i.e., responding during forced trials was not included) and that total number of responses was divided by the total time that the green lights were illuminated during choice trials. Cumulative drug intake was obtained by multiplying the unit dose of drug available during a session by the number of drug infusions delivered during that session (i.e., including the forced trial). When drug solutions were available on both levers, the percentage choice of the variable dose of remifentanil, either alone or with midazolam, response rate during choice trials, and total number of infusions during choice trials were plotted as a function of the variable dose of remifentanil. Percentage choice of the variable dose of remifentanil was calculated by dividing the number of infusions received of the variable dose by the total number of infusions received during choice trials. With the exception of midazolam alone (Fig. 2), each dose-effect curve was determined twice. To obtain the data points shown in figures, values were averaged across the last three sessions of each experimental condition. For the midazolam dose-effect curve, which was determined once, that mean was plotted in the figure; for the remaining conditions, the three-session means were averaged across the two determinations, and those means ( \pm S.E.M.) were plotted in the figures.

The effective dose of remifentanil that resulted in $50 \%$ of infusions earned for the variable dose of remifentanil was calculated by fitting a line to the linear portion of the curve and estimating the dose that would produce a $50 \%$ effect. Potency ratios were then determined by dividing the $\mathrm{ED}_{50}$ value of remifentanil alone by the $\mathrm{ED}_{50}$ value of remifentanil obtained when it was combined with midazolam. The potency of remifentanil was considered to be significantly increased when the $95 \%$ confidence intervals of the potency ratios averaged across monkeys did not include 1 . Data analyses were performed using GraphPad Prism (version 6.07 GraphPad, La Jolla, CA).

\section{Results}

When remifentanil was available on one lever and saline was available on the other lever, monkeys always received more infusions of drug than saline. There was a dosedependent increase in the number of infusions of remifentanil delivered with monkeys receiving at least 23 infusions of remifentanil and no infusions of saline when the unit dose was $0.32 \mu \mathrm{g} / \mathrm{kg} /$ infusion (Fig. 1, top). Response rates (Fig. 1, center) and intake of remifentanil (Fig. 1, bottom) also increased dose dependently and were highest when $0.32 \mu \mathrm{g} / \mathrm{kg} / \mathrm{infusion}$ remifentanil was available. In contrast to the large number of infusions of remifentanil, two of the three monkeys were less likely to self-administer midazolam when it was available on one lever and saline was available on the other lever. For example, monkey JA received no more than two infusions of any dose of midazolam (3.2-32 $\mu \mathrm{g} / \mathrm{kg} /$ infusion), and when the largest unit dose of midazolam was available, the monkey received more infusions of saline than of midazolam (Fig. 2, top left). Monkey HU responded for, on average, 4-7 infusions of midazolam, depending on the unit dose, and no more than three infusions of saline (Fig. 2, top middle). In contrast, monkey KI responded for midazolam, receiving an average of 21 infusions of $10 \mu \mathrm{g} / \mathrm{kg} /$ infusion midazolam; the number of infusions of midazolam decreased and the number of infusions of saline increased when a unit dose of $32 \mu \mathrm{g} / \mathrm{kg} / \mathrm{infusion}$ was available (Fig. 2, top right). Response rates for midazolam were much lower than for remifentanil in all monkeys, including KI (Fig. 2, middle). Total intake of midazolam 
JA
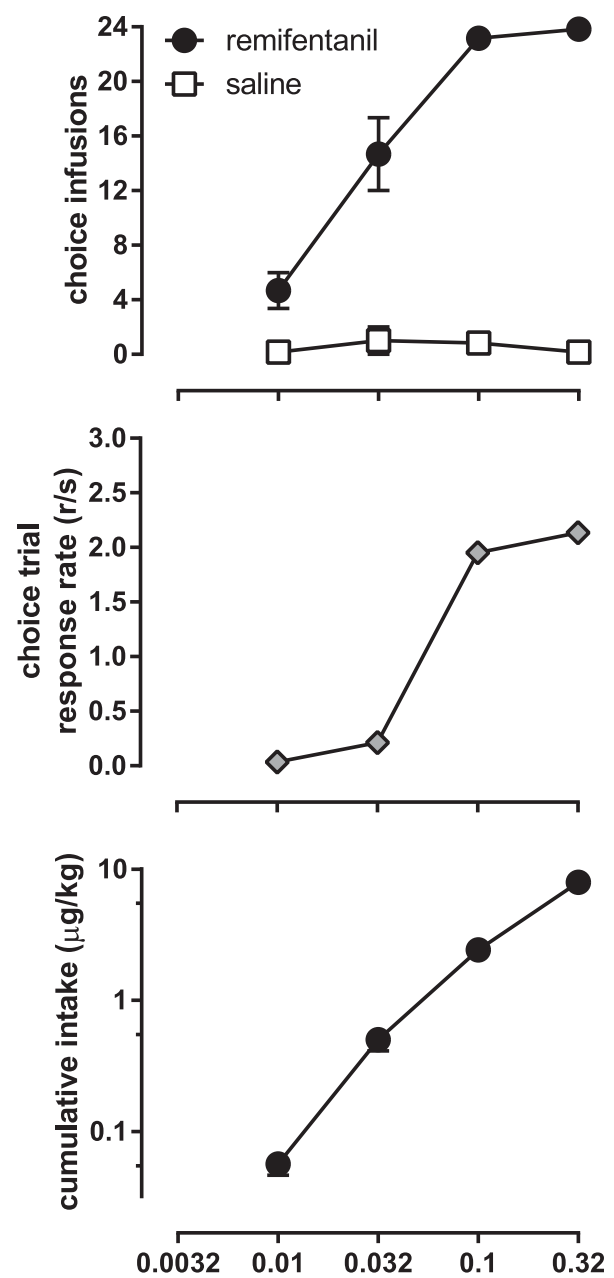

HU
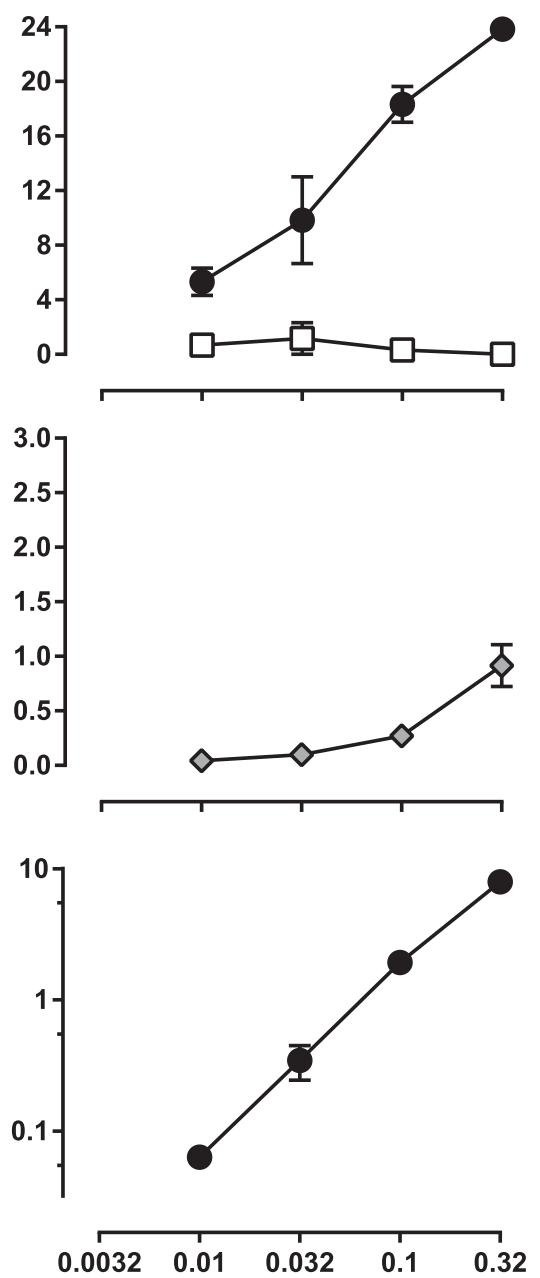

KI
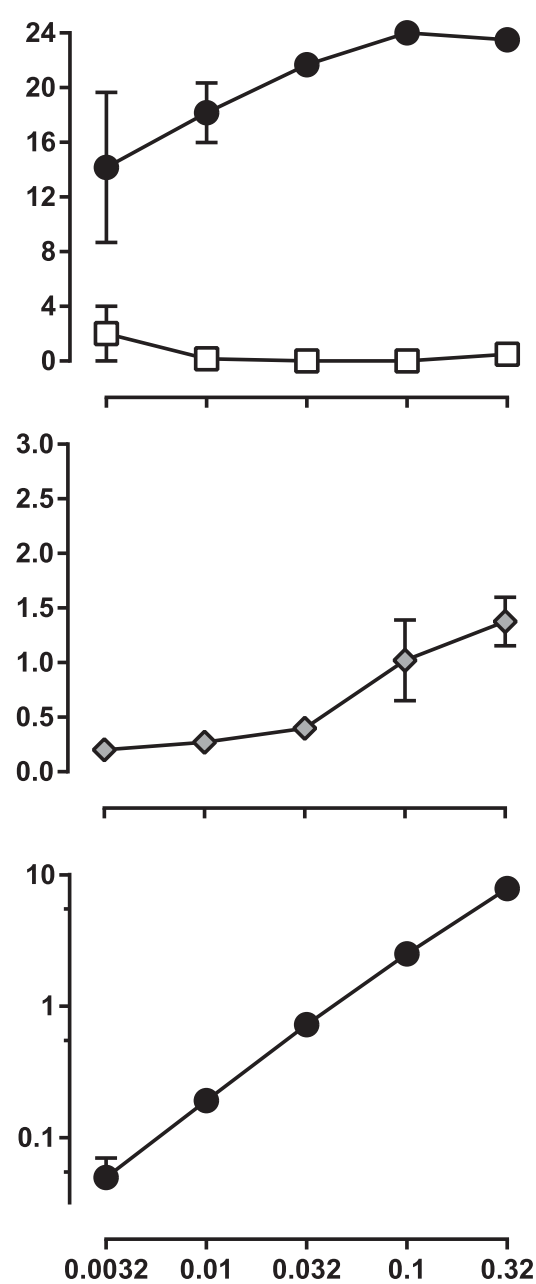

\section{remifentanil dose $(\mu \mathrm{g} / \mathrm{kg} / \mathrm{infusion})$}

Fig. 1. Number of infusions (top), response rate (middle), and total intake (bottom) in three monkeys (JA, HU, and KI) responding on one lever for delivery of remifentanil $(\bullet)$ and on a second lever for delivery of saline $(\square)$. Dose-effect curves were determined twice and data points represent the mean ( \pm S.E.M.) for two determinations of the dose-effect curve. Abscissae indicate the unit dose of remifentanil available for self-administration.

increased with unit dose in all monkeys, even for monkey JA that received very few infusions (Fig. 2, bottom).

For the remaining studies, responding on either lever resulted in the delivery of drug(s); responding on one lever delivered a fixed dose of $0.32 \mu \mathrm{g} / \mathrm{kg} / \mathrm{infusion}$ remifentanil and responding on the second lever delivered a dose of remifentanil that varied across sessions and was sometimes combined with midazolam. When remifentanil alone was available on both levers, subjects chose the larger dose (diamonds in Fig. 3, top). For example, monkeys chose $0.32 \mu \mathrm{g} / \mathrm{kg} /$ infusion remifentanil (fixed dose) when the alternative was $0.1 \mu \mathrm{g} / \mathrm{kg} / \mathrm{infusion}$ remifentanil and they chose $1 \mu \mathrm{g} / \mathrm{kg} / \mathrm{infusion}$ remifentanil over $0.32 \mu \mathrm{g} / \mathrm{kg} /$ infusion remifentanil. When $0.32 \mu \mathrm{g} / \mathrm{kg} /$ infusion was available on both levers, KI responded exclusively on one lever, whereas JA and HU responded on both levers (66.0\% and 55.6\% variable-lever choice, respectively). As the variable dose of remifentanil increased, with $0.32 \mu \mathrm{g} / \mathrm{kg} / \mathrm{infusion}$ remifentanil available on the other lever, response rates increased in monkey HU and were not markedly changed in monkeys JA and $\mathrm{KI}$ (diamonds in Fig. 3, middle); monkeys received, on average, no fewer than 23 of the 24 available infusions (diamonds in Fig. 3, bottom).

When midazolam was combined with the variable dose of remifentanil, monkeys chose the mixture over the same dose of remifentanil alone, and for some combinations of midazolam and remifentanil, they responded for the mixture over a larger dose of remifentanil alone. With a small unit dose of midazolam ( $3.2 \mu \mathrm{g} / \mathrm{kg} /$ infusion $)$ in the mixture, all three monkeys chose the combination of midazolam and $0.32 \mu \mathrm{g} / \mathrm{kg} /$ infusion remifentanil over the fixed dose of $0.32 \mu \mathrm{g} / \mathrm{kg} /$ infusion remifentanil alone (squares in Fig. 3, top). When a smaller unit dose of remifentanil $(0.1 \mu \mathrm{g} / \mathrm{kg} /$ infusion $)$ was combined with $3.2 \mu \mathrm{g} / \mathrm{kg} /$ infusion midazolam, two of the three monkeys ( $\mathrm{HU}$ and $\mathrm{KI}$ ) chose the larger dose of remifentanil available alone, although monkey JA continued to respond predominantly for the mixture. Increasing the unit dose of midazolam to $10 \mu \mathrm{g} / \mathrm{kg} /$ infusion increased responding for the mixture. In fact, monkeys chose the mixture containing $0.1 \mu \mathrm{g} / \mathrm{kg} /$ infusion remifentanil over the larger, fixed dose of remifentanil $(0.32 \mu \mathrm{g} / \mathrm{kg} / \mathrm{infusion})$ 

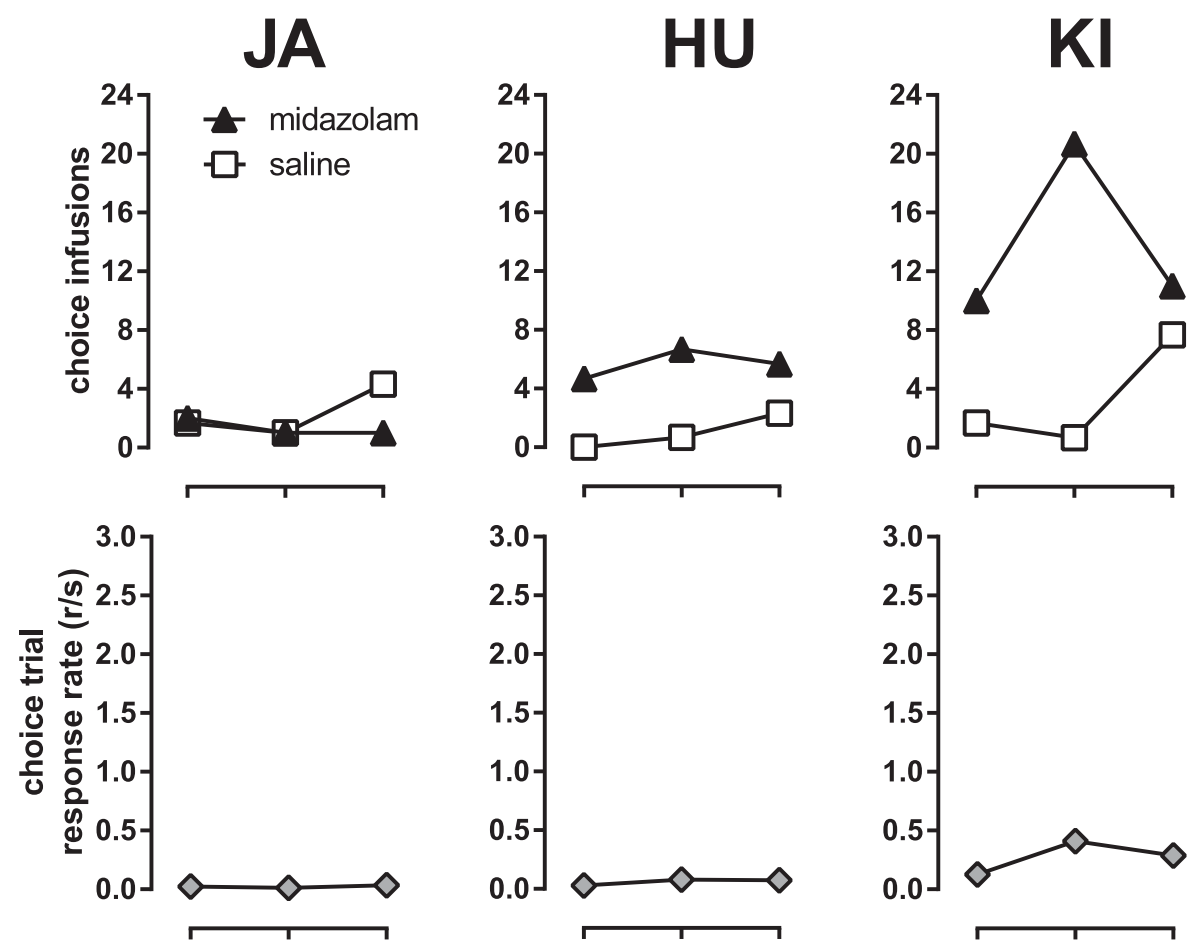

Fig. 2. Number of infusions (top), response rate (middle), and total intake (bottom) in three monkeys (JA, HU, and $\mathrm{KI}$ ) responding on one lever for delivery of midazolam $(\boldsymbol{\Lambda})$ and on a second lever for delivery of saline ( $\square$ ). Dose-effect curves were determined once. Abscissae indicate the unit dose of midazolam available for selfadministration.
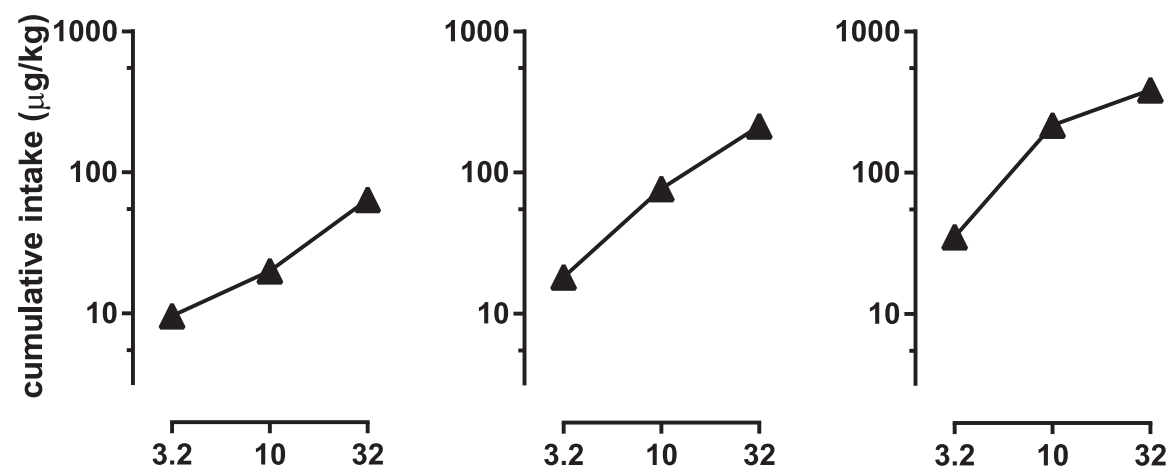

\section{midazolam dose ( $\mu \mathrm{g} / \mathrm{kg} / \mathrm{infusion})$}

available alone, resulting in a decrease in total intake of remifentanil. Monkeys could have received a total dose of $7.68 \mu \mathrm{g} / \mathrm{kg}$ remifentanil if they had responded exclusively for the fixed dose; however, when $10 \mu \mathrm{g} / \mathrm{kg} /$ infusion midazolam was combined with $0.1 \mu \mathrm{g} / \mathrm{kg} /$ infusion remifentanil, total intake of remifentanil was considerably less, ranging from 2.9 (monkey $\mathrm{KI}$ ) to $5.3 \mu \mathrm{g} / \mathrm{kg}$ (monkey HU). There was no decrease in total infusions until $32 \mu \mathrm{g} / \mathrm{kg} /$ infusion midazolam was combined with remifentanil (Fig. 3, bottom), indicating that the smaller total dose of remifentanil was due to preference for the smaller dose and not a suppression of responding. Response rates were not altered when $3.2 \mu \mathrm{g} / \mathrm{kg} /$ infusion midazolam was combined with remifentanil; however, rate-decreasing effects were evident when 10 (monkey $\mathrm{KI}$ only) or 32 (all three monkeys) $\mu \mathrm{g} / \mathrm{kg} /$ infusion midazolam was combined with remifentanil (Fig. 3, middle).

The overall effect of combining midazolam and remifentanil was to increase the potency of remifentanil, as evidenced by leftward shifts in the remifentanil dose-effect curve in all monkeys (Fig. 3, top; Table 1). When monkeys chose between variable doses of remifentanil alone and the fixed dose of $0.32 \mu \mathrm{g} / \mathrm{kg} /$ infusion remifentanil, the $\mathrm{ED}_{50}$ values for $\mathrm{JA}, \mathrm{HU}$, and KI were $0.27,0.26$, and $0.17 \mu \mathrm{g} / \mathrm{kg} /$ infusion remifentanil, respectively. Combining $3.2 \mu \mathrm{g} / \mathrm{kg} / \mathrm{infusion}$ midazolam with remifentanil decreased $\mathrm{ED}_{50}$ values to 0.09 and $0.16 \mu \mathrm{g} / \mathrm{kg} /$ infusion remifentanil for JA and HU, although the $\mathrm{ED}_{50}$ value $(0.18 \mu \mathrm{g} / \mathrm{kg} /$ infusion $)$ was not changed for monkey KI. Increasing the midazolam dose to $10 \mu \mathrm{g} / \mathrm{kg} / \mathrm{infusion}$ and then to $32 \mu \mathrm{g} / \mathrm{kg} /$ infusion reduced the $\mathrm{ED}_{50}$ values in all three monkeys and increased the potency ratios. Adding $10 \mu \mathrm{g} / \mathrm{kg} /$ infusion midazolam to remifentanil significantly shifted the remifentanil dose-effect curve leftward, as evidenced by a potency ratio (95\% confidence interval) of $4.4(2.2,6.6)$ with a $95 \%$ confidence interval that did not include 1 .

\section{Discussion}

Opioid overdose has become a public health crisis that is being driven primarily by abuse of prescription opioids and heroin. One factor that appears to contribute to both overdose 

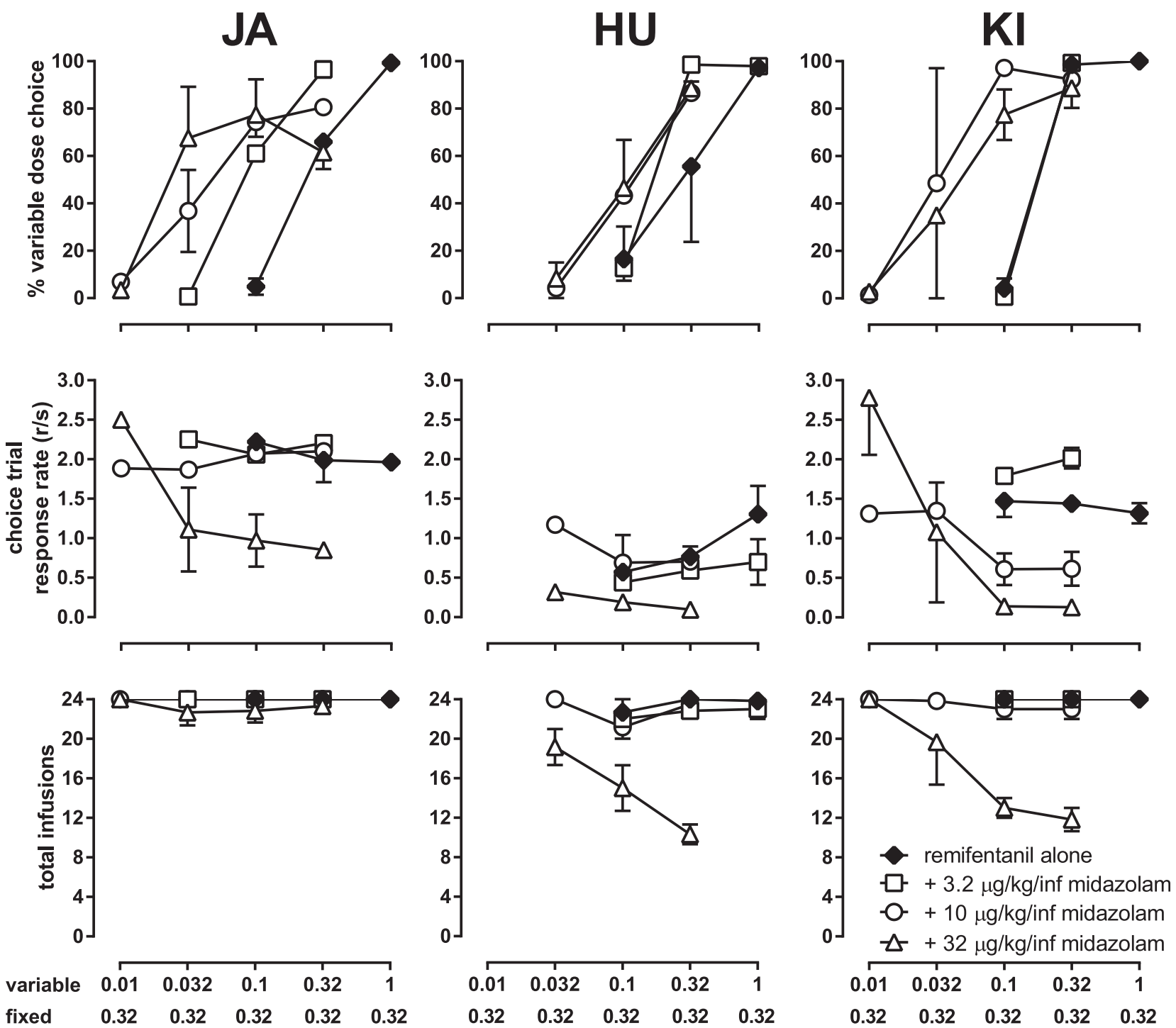

\section{remifentanil dose ( $\mu \mathrm{g} / \mathrm{kg} / \mathrm{infusion})$}

Fig. 3. Percentage choice of the variable dose of remifentanil (top), response rate during choice trials (middle), and total infusions (bottom) in three monkeys (JA, HU, and KI) responding on one lever for delivery of a fixed dose of $0.32 \mu \mathrm{g} / \mathrm{kg} /$ infusion remifentanil and on a second lever for delivery of a variable dose of remifentanil alone $(\downarrow)$ or combined with midazolam (open symbols). Dose-effect curves were determined twice and data points represent the mean ( \pm S.E.M.) for two determinations of the dose-effect curve. Abscissae indicate the unit dose of remifentanil. Missing error bars indicate the variance is encompassed by the point or there was only a single determination for a given dose (monkeys JA and KI: $0.01 \mu \mathrm{g} / \mathrm{kg} / \mathrm{infusion}$ remifentanil $+10 \mu \mathrm{g} / \mathrm{kg} / \mathrm{infusion}$ midazolam)

and abuse is concurrent use of benzodiazepines; however, relatively few laboratory studies have investigated selfadministration of opioid/benzodiazepine mixtures. The current study established a concurrent-choice procedure in which monkeys could choose between remifentanil alone and a mixture of remifentanil and midazolam. Monkeys generally chose the mixture over the same dose of remifentanil alone, and for some dose combinations ( $10 \mu \mathrm{g} / \mathrm{kg} /$ infusion midazolam

TABLE 1

$\mathrm{ED}_{50}$ values and potency ratios for percent choice of variable remifentanil dose ( $\left.\mu \mathrm{g} / \mathrm{kg} / \mathrm{infusion}\right)$

\begin{tabular}{|c|c|c|c|c|c|c|c|}
\hline \multirow{2}{*}{ Subject } & \multirow{2}{*}{$\frac{\text { Remifentanil Alone }}{\mathrm{ED}_{50}}$} & \multicolumn{2}{|c|}{$+3.2 \mu \mathrm{g} / \mathrm{kg} /$ infusion Midazolam } & \multicolumn{2}{|c|}{$+10 \mu \mathrm{g} / \mathrm{kg} /$ infusion Midazolam } & \multicolumn{2}{|c|}{$+32 \mu \mathrm{g} / \mathrm{kg} /$ infusion Midazolam } \\
\hline & & $\mathrm{ED}_{50}$ & Potency ratio & $\mathrm{ED}_{50}$ & Potency ratio & $\mathrm{ED}_{50}$ & Potency ratio \\
\hline JA & 0.27 & 0.09 & 3.0 & 0.05 & 5.4 & 0.02 & 13.5 \\
\hline $\mathrm{HU}$ & 0.26 & 0.16 & 1.6 & 0.12 & 2.2 & 0.11 & 2.4 \\
\hline $\mathrm{KI}$ & 0.17 & 0.18 & 0.9 & 0.03 & 5.7 & 0.05 & 3.4 \\
\hline Mean $(95 \%$ CI $)$ & & & $1.8(0.6,3.0)$ & & $4.4(2.2,6.6)^{*}$ & & $6.4(-0.5,13.4)$ \\
\hline
\end{tabular}

* Remifentanil dose-effect curve is significantly changed because 95\% confidence interval (CI) does not include 1 . 
and $0.1 \mu \mathrm{g} / \mathrm{kg} /$ infusion remifentanil), they chose the mixture over a larger dose of remifentanil alone. Thus, under these laboratory conditions, monkeys avidly self-administered an opioid when it was mixed with a benzodiazepine.

Most abusers take multiple drugs concurrently, and they often combine opioids and benzodiazepines. Abusers often report that they use these drugs together because benzodiazepines enhance the effects of opioids (Stitzer et al., 1981; Iguchi et al., 1993), and these findings are supported by human laboratory studies reporting increased subjective effects of opioids when combined with benzodiazepines (Preston et al., 1984; Farré et al., 1998; Spiga et al., 2001; Lintzeris et al., 2006). The current study was not designed to examine increases in reinforcing effectiveness, although these results suggest that by taking benzodiazepines with opioids, abusers might experience effects that would normally require larger doses of the opioid alone. That is, they might need a smaller dose of opioid (with a benzodiazepine) to achieve a particular effect. Future studies will compare other doses of remifentanil and other opioids to opioid/benzodiazepine mixtures to determine whether benzodiazepines generally change the potency of opioids and whether they can alter the reinforcing effectiveness of opioids.

In addition to increasing the potency or effectiveness of opioids, benzodiazepines might have other important effects that cause people to use them with opioids. For example, the use of prescription opioids for chronic pain has increased over the last 20 years, and one consequence of increased use is that these drugs are readily available for diversion and misuse. In addition to increasing the prevalence of opioid abuse, more people are physically dependent on opioids due to long-term abuse or clinical use for chronic pain. Anxiety and sleep disturbances often occur in opioid abusers and pain patients. Consequently, people who use opioids might also take benzodiazepines to self-medicate for anxiety or insomnia (Gelkopf et al., 1999; Chen et al., 2011). Although humans might coabuse opioids and benzodiazepines for purposes of self-medication, it is unlikely that monkeys chose to selfadminister mixtures for therapeutic purposes. Thus, data from monkeys suggest that treating underlying anxiety or sleep disorders does not entirely account for opioid/benzodiazepine coabuse.

Although it is well established that humans take opioids and benzodiazepines concurrently, this phenomenon had not previously been reported in laboratory studies. Other drugs are also abused with opioids, and some mixtures are particularly popular; the current study used an approach that was previously shown to be sensitive to drugs that are commonly abused together. For example, polydrug abusers often combine opioids with cocaine, and several strategies have been used in the preclinical laboratory to compare the reinforcing effects of opioid/cocaine mixtures to those of each drug alone, including the use of progressive ratio schedules of reinforcement (e.g., Woolverton et al., 2008) and behavioral economics (e.g., Winger et al., 2006). Among all of the procedures that have been used to study drug combinations, concurrent-choice procedures seem to be particularly sensitive to opioid/cocaine mixtures (Freeman and Woolverton 2011). In the current study, monkeys responded at high rates and received the maximum number of infusions of remifentanil; however, although benzodiazepines, including midazolam, can function as positive reinforcers under some conditions [e.g., oral self-administration (Gomez et al., 2002); intravenous selfadministration (Gerak et al., 2001; Ator et al., 2005; Broadbear et al., 2005; Fischer et al., 2016)], responding for benzodiazepines is generally much less than responding for other drugs of abuse, including other drugs with sedative/ hypnotic effects (methohexital and ethanol; e.g., Griffiths and Weerts, 1997; Broadbear et al., 2005). In the current study, rates of responding for midazolam alone were low for all monkeys. Despite these reduced rates, monkey KI received nearly as many infusions of midazolam as remifentanil; however, the number of infusions for the other two monkeys was considerably lower for midazolam, compared with remifentanil. Thus, although midazolam can function as a positive reinforcer, responding for remifentanil alone was greater than responding for midazolam alone, which is consistent with previous studies.

Although two-response, self-administration procedures have been used to examine preference for mixtures, those studies generally investigated two drugs that alone maintain high rates of responding, such as opioids and cocaine. Fewer studies have examined combinations of drugs that differ markedly in reinforcing effectiveness, as was the case with remifentanil and midazolam in the current study. Nevertheless, this procedure was sensitive enough to detect preference for these mixtures. When remifentanil alone was concurrently available on two levers and the only difference was unit dose, monkeys responded for the larger dose. Adding midazolam to remifentanil increased preference for the mixture. With a fixed unit dose of $0.32 \mu \mathrm{g} / \mathrm{kg} /$ infusion remifentanil alone available on the other lever, monkeys chose some mixtures nearly exclusively. This preference did not seem to depend on the reinforcing effects of midazolam alone in individual monkeys because choice of the mixture was similar in monkey JA, that did not respond for midazolam alone (Fig. 2, left), and monkey $\mathrm{KI}$, that responded to receive almost as many infusions of midazolam alone as of remifentanil alone (Fig. 2, right). One advantage of the concurrent choice procedure is that preference is independent of response rate. In the current study, $10 \mu \mathrm{g} / \mathrm{kg} / \mathrm{infusion}$ (one monkey) and $32 \mu \mathrm{g} / \mathrm{kg} / \mathrm{infusion}$ midazolam (all monkeys) markedly decreased response rates, perhaps due to accumulation of midazolam during sessions. Overall, these results underscore the value of concurrentchoice procedures for studying self-administration of drug mixtures and extend the use to these procedures to situations in which the two drugs in the mixture vary markedly in terms of their reinforcing effectiveness.

These studies accomplished a number of important goals, including establishing a procedure to examine selfadministration of opioid/benzodiazepine mixtures and showing that all monkeys chose mixtures of remifentanil and midazolam over larger doses of remifentanil alone. As a result, remifentanil intake decreased as the dose of remifentanil in the mixture decreased. Monkeys could receive more remifentanil by responding for the larger unit dose alone; instead, they reliably responded for the mixture and began responding exclusively for remifentanil alone only when the remifentanil dose in the mixture was very small. Thus, when combined with midazolam, the remifentanil dose-effect curve was shifted to the left, indicating an increased potency of remifentanil.

In summary, preference for mixtures of opioids and benzodiazepines is evident using a two-response choice procedure. For some dose combinations, monkeys prefer the mixture to 
larger unit doses of remifentanil alone; under these conditions, monkeys could receive a larger total dose of remifentanil by shifting responding away from the mixture. That they continue to respond for the mixture suggests that midazolam increases the potency of remifentanil. Further studies are needed to determine whether midazolam also increases the reinforcing effectiveness of remifentanil.

\section{Acknowledgments}

The authors thank E. S. Desarno and S. A. Howard for expert technical assistance.

\section{Authorship Contributions}

Participated in research design: Weed, France, and Gerak.

Conducted experiments: Weed.

Performed data analysis: Weed and Gerak.

Wrote or contributed to the writing of the manuscript: Weed, France, and Gerak.

\section{References}

Ator NA, Griffiths RR, and Weerts EM (2005) Self-injection of flunitrazepam alone and in the context of methadone maintenance in baboons. Drug Alcohol Depend 78: 113-123.

Bleich A, Gelkopf M, Schmidt V, Hayward R, Bodner G, and Adelson M (1999) Correlates of benzodiazepine abuse in methadone maintenance treatment. A 1 year prospective study in an Israeli clinic. Addiction 94:1533-1540.

Broadbear JH, Winger G, and Woods JH (2005) Self-administration of methohexital, midazolam and ethanol: effects on the pituitary-adrenal axis in rhesus monkeys. Psychopharmacology (Berl) 178:83-91.

Chen KW, Berger CC, Forde DP, D'Adamo C, Weintraub E, and Gandhi D (2011) Benzodiazepine use and misuse among patients in a methadone program. BMC Psychiatry 11:90.

Collins GT, Gerak LR, Javors MA, and France CP (2016) Lorcaserin reduces the discriminative stimulus and reinforcing effects of cocaine in rhesus monkeys. $J$ Pharmacol Exp Ther 356:85-95.

Compton WM, Jones CM, and Baldwin GT (2016) Relationship between nonmedical prescription-opioid use and heroin use. N Engl J Med 374:154-163.

Darke S, Ross J, Mills K, Teesson M, Williamson A, and Havard A (2010) Benzodiazepine use among heroin users: baseline use, current use and clinical outcome. Drug Alcohol Rev 29:250-255.

Eiroa-Orosa FJ, Haasen C, Verthein U, Dilg C, Schäfer I, and Reimer J (2010) Benzodiazepine use among patients in heroin-assisted vs. methadone maintenance treatment: findings of the German randomized controlled trial. Drug Alcohol Depend 112:226-233.

Farré M, Terán MT, Roset PN, Mas M, Torrens M, and Camí J (1998) Abuse liability of flunitrazepam among methadone-maintained patients. Psychopharmacology (Berl) 140:486-495.

Fischer BD, Platt DM, Rallapalli SK, Namjoshi OA, Cook JM, and Rowlett JK (2016) Antagonism of triazolam self-administration in rhesus monkeys responding under a progressive-ratio schedule: In vivo apparent $\mathrm{pA}_{2}$ analysis. Drug Alcohol Depend 158:22-29.

Freeman KB and Woolverton WL (2011) Self-administration of cocaine and remifentanil by monkeys: choice between single drugs and mixtures. Psychopharmacology (Berl) 215 : $281-290$.

Gelkopf M, Bleich A, Hayward R, Bodner G, and Adelson M (1999) Characteristics of benzodiazepine abuse in methadone maintenance treatment patients: a 1 year prospective study in an Israeli clinic. Drug Alcohol Depend 55:63-68.

Gerak LR, Collins GT, and France CP (2016) Effects of lorcaserin on cocaine and methamphetamine self-administration and reinstatement of responding previously maintained by cocaine in rhesus monkeys. J Pharmacol Exp Ther 359:383-391.

Gerak LR, Galici R, and France CP (2009) Self administration of heroin and cocaine in morphine-dependent and morphine-withdrawn rhesus monkeys. Psychopharmacology (Berl) 204:403-411.

Gerak LR, Woolverton WL, Nader MA, Patrick GA, Harris LS, Winger G, Woods JH and France CP (2001) Behavioral effects of flunitrazepam: reinforcing and discriminative stimulus effects in rhesus monkeys and prevention of withdrawal signs in pentobarbital-dependent rats. Drug Alcohol Depend 63:39-49.

Ghitza UE, Epstein DH, and Preston KL (2008) Self-report of illicit benzodiazepine use on the Addiction Severity Index predicts treatment outcome. Drug Alcohol Depend 97:150-157.

Gomez TH, Roache JD, and Meisch RA (2002) Orally delivered alprazolam, diazepam, and triazolam as reinforcers in rhesus monkeys. Psychopharmacology (Berl) 161:86-94.

Gossop M, Marsden J, Stewart D, and Rolfe A (1999) Treatment retention and 1 year outcomes for residential programmes in England. Drug Alcohol Depend 57:89-98.

Griffiths RR and Weerts EM (1997) Benzodiazepine self-administration in humans and laboratory animals-implications for problems of long-term use and abuse. Psychopharmacology (Berl) 134:1-37.

Haney M (2009) Self-administration of cocaine, cannabis and heroin in the human laboratory: benefits and pitfalls. Addict Biol 14:9-21.

Iguchi MY, Handelsman L, Bickel WK, and Griffiths RR (1993) Benzodiazepine and sedative use/abuse by methadone maintenance clients. Drug Alcohol Depend 32: $257-266$.

Kerr T, Fairbairn N, Tyndall M, Marsh D, Li K, Montaner J, and Wood E (2007) Predictors of non-fatal overdose among a cohort of polysubstance-using injection drug users. Drug Alcohol Depend 87:39-45.

Ko MC, Terner J, Hursh S, Woods JH, and Winger G (2002) Relative reinforcing effects of three opioids with different durations of action. J Pharmacol Exp Ther 301:698-704.

Koek W, Gerak LR, and France CP (2015) Effects of amphetamine, morphine, and CP 55,940 on Go/No-Go task performance in rhesus monkeys. Behav Pharmacol 26: $481-484$.

Lavie E, Fatséas M, Denis C, and Auriacombe M (2009) Benzodiazepine use among opiate-dependent subjects in buprenorphine maintenance treatment: correlates of use, abuse and dependence. Drug Alcohol Depend 99:338-344.

Lintzeris N, Mitchell TB, Bond A, Nestor L, and Strang J (2006) Interactions on mixing diazepam with methadone or buprenorphine in maintenance patients. $J$ Clin Psychopharmacol 26:274-283.

Maguire DR, Gerak LR, and France CP (2013) Delay discounting of food and remifentanil in rhesus monkeys. Psychopharmacology (Berl) 229:323-330.

Peles E, Schreiber S, and Adelson M (2006) Factors predicting retention in treatment: 10-year experience of a methadone maintenance treatment (MMT) clinic in Israel. Drug Alcohol Depend 82:211-217.

Preston KL, Griffiths RR, Stitzer ML, Bigelow GE, and Liebson IA (1984) Diazepam and methadone interactions in methadone maintenance. Clin Pharmacol Ther 36: 534-541.

Rudd RA, Aleshire N, Zibbell JE, and Gladden RM (2016) Increases in drug and opioid overdose deaths-United States, 2000-2014. MMWR Morb Mortal Wkly Rep 64:1378-1382

San L, Tato J, Torrens M, Castillo C, Farré M, and Camí J (1993) Flunitrazepam consumption among heroin addicts admitted for in-patient detoxification. Drug Alcohol Depend 32:281-286.

Skolnick P and Volkow ND (2016) Re-energizing the development of pain therapeutics in light of the opioid epidemic. Neuron 92:294-297.

Spiga R, Huang DB, Meisch RA, and Grabowski J (2001) Human methadone selfadministration: effects of diazepam pretreatment. Exp Clin Psychopharmacol 9: $40-46$.

Stitzer ML, Griffiths RR, McLellan AT, Grabowski J, and Hawthorne JW (1981) Diazepam use among methadone maintenance patients: patterns and dosages. Drug Alcohol Depend 8:189-199.

Ward SJ, Morgan D, and Roberts DCS (2005) Comparison of the reinforcing effects of cocaine and cocaine/heroin combinations under progressive ratio and choice schedules in rats. Neuropsychopharmacology 30:286-295.

Winger G, Galuska CM, Hursh SR, and Woods JH (2006) Relative reinforcing effects of cocaine, remifentanil, and their combination in rhesus monkeys. J Pharmaco Exp Ther 318:223-229.

Woody GE, Mintz J, O'Hare K, O'Brien CP, Greenstein RA, and Hargrove E (1975) Diazepam use by patients in a methadone program-how serious a problem? $J$ Psychedelic Drugs 7:373-379.

Woolverton WL, Wang Z, Vasterling T, and Tallarida R (2008) Self-administration of cocaine-remifentanil mixtures by monkeys: an isobolographic analysis. Psychopharmacology (Berl) 198:387-394.

Address correspondence to: Lisa R Gerak, Department of Pharmacology, University of Texas Health Science Center at San Antonio, 7703 Floyd Curl Dr., Mail Code 7764, San Antonio, TX 78229. E-mail: gerak@uthscsa.edu 